\title{
Cyclooxygenase I and II inhibitors distinctly enhance hippocampal- and cortex-dependent cognitive functions in mice
}

\author{
HUMA SYED ${ }^{1}$, MUHAMMAD FAISAL IKRAM ${ }^{2}$, AHMED YAQINUDDIN $^{2}$ and TOUQEER AHMED ${ }^{1}$ \\ ${ }^{1}$ Neurobiology Laboratory, Atta-ur-Rahman School of Applied Biosciences, National University of Sciences and Technology, \\ Islamabad 44000, Pakistan; ${ }^{2}$ College of Medicine, Alfaisal University, Riyadh 11533, Saudi Arabia
}

Received December 26, 2014; Accepted August 17, 2015

DOI: $10.3892 / \mathrm{mmr} .2015 .4351$

\begin{abstract}
Cyclooxygenase (COX) enzymes are expressed in the brain; however, their role in hippocampus-dependent and cortex-dependent cognitive functions remains to be fully elucidated. The aim of the present study was to comparatively investigate the effects of piroxicam, a selective COX-I inhibitor, and celecoxib, a selective COX-II inhibitor, on cognitive functions in an $\mathrm{AlCl}_{3}$-induced neurotoxicity mouse model to understand the specific role of each COX enzyme in the hippocampus and cortex. The $\mathrm{AlCl}_{3}(250 \mathrm{mg} / \mathrm{kg})$ was administered to the mice in drinking water and the drugs were administered in feed for 30 days. Assessments of memory, including a Morris water maze, social behavior and nesting behavior were performed in control and treated mice. The RNA expression of the COX enzymes were analyzed using reverse transcription-quantitative polymerase chain reaction analysis. An ex-vivo 2,2-Diphenyl-1-picrylhydrazyl assay was performed in the hippocampus and cortex. Following 30 days of treatment with thedrugs, the mice in the celecoxib- and piroxicam-treated groups exhibited enhanced learning $(6.84 \pm 0.76$ and $9.20 \pm 1.08$, respectively), compared with the $\mathrm{AlCl}_{3}$-induced neurotoxicity group (21.14 \pm 0.76$)$ on the fifth day of the Morris water maze test. Celecoxib treatment improved social affiliation in the $\mathrm{AlCl}_{3}$-induced neurotoxicity group, the results of which were superior to piroxicam. Piroxicam led to better improvement in nesting score in the $\mathrm{AlCl}_{3}$-induced neurotoxicity group. Both drugs decreased the expression levels of COX-I and COX-II in the hippocampus and cortex, and rescued oxidative stress levels. These findings suggested that each drug distinctly affected cognitive functions, highlighting the distinctive roles of COX-I and COX-II in learning and memory.
\end{abstract}

Correspondence to: Dr Touqeer Ahmed, Neurobiology Laboratory, Atta-ur-Rahman School of Applied Biosciences, National University of Sciences and Technology, Sector H-12, Islamabad 44000, Pakistan

E-mail: touqeer.aahmed@gmail.com touqeer.ahmed@asab.nust.edu.pk

Key words: cyclooxygenase, inflammation, social behavior, celecoxib, piroxicam

\section{Introduction}

Non steroidal anti-inflammatory drugs (NSAIDs) inhibit cyclooxygenase (COX) enzymes and are used extensively to treat multiple illnesses (1). There are several neurodegenerative disorders, in which concurrent inflammatory stress occurs (1). The importance of neuroinflammation in various neurodegenerative conditions is supported by evidence from post mortem analyses, accompanied by microglial activation and reactive astrocytes (2-4), suggesting the importance of COX enzymes. Several studies have suggested that anti-inflammatory drugs, particularly NSAIDs, appear to be beneficial in slowing the progression of neurodegenerative diseases, including Alzheimer's disease (AD) (5-7), by inhibiting inflammatory responses (8-10). NSAIDs exert their anti-inflammatory effect by inhibiting COX isoforms (11). COX is a homodimer membrane glycoprotein associated with a heme group involved in enzymatic activities (12). Two important isoforms of COX have been identified, COX-I and COX-II (13). Several studies have suggested the beneficial role of COX-II in AD, as the expression and activity of COX-II is increased in early stages of $\mathrm{AD}$, determining the primary protection of NSAIDs in preventing the earlier steps leading to neurodegeneration (14).

There has been controversy regarding the role of COX-I either as a protective or pro-inflammatory agent. COX-I is prominently expressed in microglia (15). Microglial activation is reported following aluminium ( $\mathrm{Al}$ ) administration (16), suggesting the involvement of COX-1 following Al-induced injury. COX-I is actively involved in immunoregulation of central nervous system $(1,17,18)$ and its deletion reduces neuro-inflammation and neuronal damage induced by $\mathrm{A} \beta$ (19). However, enhanced activity of COX-1 is reported as a source of oxidative stress in $A \beta$-mediated neurotoxicity (13). Multiple studies (19-22) have indicated the active involvement of COX-I in brain injury induced by pro-inflammatory stimuli, including $\mathrm{A} \beta$.

COX-II is expressed in the brain under normal conditions (23), while it is an inducible enzyme in other tissues and is expressed in response to pro-inflammatory stimuli (24). COX-II is prominently expressed in hippocampal and cortical glutamatergic neurons (25), but not in astrocytes and microglial cells (26), suggesting its distinctive role, compared with COX-I. COX-II, which is predominantly present in neurons, is important in regulating brain functions, including synaptic 
plasticity $(27,28)$, however, its specific role in the hippocampus and cortex, which may be involved in cognitive functions, remains to be elucidated. In $\mathrm{AD}$, neuronal levels of COX-II have been found to be elevated either in early stages $(15,29,30)$ or decreased in later stages (31). An association between the induction of COX-II and neuronal degeneration following stimulation of glutamate seizures (32) and spreading of depression waves (33) has also been reported, however, the exact role remains to be elucidated.

Several evidence has supported the protective role of NSAIDs, which inhibit COX-I and COX-II in diseases, including AD, gastric cancer and colorectal cancer (34). Therefore, the balance between COX-I and COX-II may be important to provide balance between the inflammatory response and synaptic plasticity (23). The present study was performed to investigate the distinctive role of COX enzymes in hippocampus- and cortex-dependent cognitive function in Al-induced neurotoxicity. Al is a widely used metal and is known as a neurotoxic agent (35). Al causes impaired neurotransmission, oxidative stress (35) and increased lipid peroxidation (36). Studies showed that Al is responsible for the cognitive impairment $(37,38)$. Epidemiologically, there is an association between chronic $\mathrm{Al}$ exposure and the incidence of AD (39), and furthermore, elevated levels of Al have been reported in the brains of AD patients (40).

To understand the role of COX enzyme inhibition in cognitive function, the present study administered mice with piroxicam and celecoxib at specific doses to inhibit the COX enzymes and to examine their contribution in hippocampaland cortex-dependent cognitive functions. This investigation aimed to determine the distinct roles of COX-I and COX-II and examine the effects of celecoxib and piroxicam on organizational behavior, sociability, depression, anxiety and oxidative stress, which is a hallmark of $\mathrm{AlCl}_{3}$-induced neurotoxicity.

\section{Materials and methods}

Drugs and chemicals. Aluminium Chloride hexa hydrate (cat. no AL0770) was purchased from Scharlab (Barcelona, Spain). Celecoxib $100 \mathrm{mg}$ capsules (cat. no. 064C01) and piroxicam $20 \mathrm{mg}$ capsules (cat. no. 12C018) were purchased from Getz Pharma Private Limited (Karachi, Pakistan) and Global Pharmaceuticals (Chalfont, PA, USA), respectively. 2,2-Diphenyl-1-picrylhydrazyl (DPPH; cat. no. 101087701) and diethylether (cat. no. 676845) was obtained from Sigma-Aldrich (St. Louis, MO, USA).

Animals. Male Balb/c mice weighing 35-45 g were provided by Amson Vaccines and Pharma, Ltd. (Islamabad, Pakistan). All experiments performed complied with the rulings of the Institute of Laboratory Animal Resources, Commission on Life Sciences, National Research Council (1996) (41) and the protocol was approved by the ethical committee for research on animals (Internal Review Board, Atta-ur-Rahman School of Applied Biosciences, National University of Sciences and Technology, Islamabad, Pakistan). The animals were maintained in the animal house (three mice/cage) at Atta-ur-Rahman School of Applied Biosciences, National University of Sciences and Technology, under controlled conditions $\left(23-25^{\circ} \mathrm{C} ; 10 \mathrm{~h}\right.$ light/dark cycle), and house separately according to the group to which they pertain. The experimental mice were provided with access to distilled water and a standard diet ad libitum.

Drug administration. In the present study a previously reported mouse model was used (42) with certain modifications. A total of four groups of animals were included, in which treatment was performed in to the respective groups for a duration of 30 days; I) Control group, 10 animals were provided with distilled water and a standard diet; II) $\mathrm{AlCl}_{3}$-induced neurotoxicity group: 10 animals were administered with $\mathrm{AlCl}_{3}(250 \mathrm{mg} / \mathrm{kg} / \mathrm{day})$ dissolved in distilled water; III) Celecoxib-treated group $\left(\mathrm{AlCl}_{3}+\mathrm{Cel}\right)$, 10 animals were provided with $\mathrm{AlCl}_{3}(250 \mathrm{mg} / \mathrm{kg} / \mathrm{day})$ dissolved in distilled water, and celecoxib was provided in the feed at the dose of $15.6 \mathrm{mg} / \mathrm{kg}$ body weight per day; IV) piroxicam-treated group $\left(\mathrm{AlCl}_{3}+\mathrm{Pxm}\right), 10$ animals were provided with $\mathrm{AlCl}_{3}(250 \mathrm{mg} / \mathrm{kg} /$ day $)$ dissolved in distilled water and piroxicam was provided in the feed at a dose of $12.5 \mathrm{mg} / \mathrm{kg}$ body weight per day. The administration doses for the Al and the drugs were calculated based on the water and diet consumption of the animals prior to initiation of the experiments in the present study. None of treatment approaches affected the water or food intake of the mice, or affected weight changes in the groups of mice (data not shown).

\section{Behavioral assessment}

Morris water maze test for assessment of spatial memory. The procedure for assessing spatial reference memory was the same as that described previously (43) with modifications. On the 25th day of treatment, the animals were subjected to a Morris water maze test, which continued until the end of the experiment. The experimental apparatus used was comprised of a circular water tank filled with water, with an invisible platform placed below the surface of the water. The temperature of the water was $21-23^{\circ} \mathrm{C}$, and the water was placed in an assessment room and clues external to the maze were visible from pool for spatial orientation by mice. These clues were maintained constant throughout the task. The pool was divided into four equal quadrants. During spatial reference memory training, the platform was always placed in the same spatial location of the pool and the releasing positions of the mice were changed in every trial. The mice received five trials per day for consecutive five days. Each trial duration was $60 \mathrm{sec}$, with an inter trial interval of 10 mins. The time taken by the mouse to reach the platform was recorded.

Social preference test. The assessment of social preference used a previously described method (44). Two sessions of 10 min were performed, with 20 min gap between them. In the first session, the test animal was exposed to a mouse, which was confined to a small closed cage, while the second cage in the testing box was empty. The mouse was allowed to interact with the mouse and an empty cage. Following the first session, the animal was returned back to its housing cage for $20 \mathrm{~min}$. During the second session, the stranger mouse was placed in the empty cage and the test mouse was allowed to interact and the time of interaction was recorded. The social novel preference was recorded and the discrimination index (DI) for the two sessions was calculated; which is the ratio between the time spent with mouse A (session I) or stranger mouse (session 
Table I. List of primers used in quantitative polymerase chain reaction analysis.

\begin{tabular}{llr}
\hline Gene & \multicolumn{1}{c}{ Primer sequence $\left(5^{\prime}-3^{\prime}\right)$} & Annealing temp $\left({ }^{\circ} \mathrm{C}\right)$ \\
\hline Actin & Forward: GCCTTCCTTCTTGGGTATGG & 55 \\
& Reverse: CAGCTCAGTAACAGTCCGC & 32 \\
COX-1 & Forward: CTACATCAGCTGGGAGTCCT & 55 \\
& Reverse: CGTCCAGCACCTGGTACTTA & 35 \\
COX-2 & Forward: CAGGTCATTGGTGGAGAGG & 54 \\
& Reverse: CATGTTCCAGGAGGATGGAG & 35 \\
\hline
\end{tabular}

COX, cyclooxygenase.

II) and the total interaction time, according to the following equation: $\mathrm{DI}=$ time spent with mouse $\mathrm{A}$ or mouse $\mathrm{B} /$ total time of interaction.

Nesting behavior. Nesting behavior was assessed, as described earlier (45) and the nest was scored from 0-5. Score 1,>90\% cotton was untouched by mouse; score $2,50-90 \%$ of cotton was torn up; score 3 , mostly shredded cotton.; score 4 , completely shredded cotton only with one or 2 walls. Score 5, walls higher than mouse body height with perfect nest. Assessment was performed in individual cages, normal bedding was used and each cage was provided with $4 \mathrm{~g}$ of cotton for making a nest. The mice were placed in these cages with cotton provided overnight, and the results were assessed the following day.

Reverse transcription-quantitative polymerase chain reaction (RT-qPCR) for RNA expression analysis. The protocol was adopted as explained earlier (46) to examine the effect of COX inhibitors on gene expression following treatment with respective drugs. The animals were sacrificed by decapitation under diethylether anesthesia, and their brains (50-100 mg; four samples/group) were isolated to extract the hippocampus and cortex. TRIzol was used to extract total RNA. The quality of the RNA was assessed by running on agarose gel to obtain two ribosomal RNA bands, and the quantity was determined using a spectrophotometer (Optima SP300; Optima Inc., Tokyo, Japan). Equal quantities of RNA were used (1 $\mu \mathrm{g}$ RNA in $40 \mu \mathrm{l}$ of reaction mixture) for RT into cDNA. cDNA (3 $\mu \mathrm{l})$ was used for the PCR reactions with at total reaction mixture $(10 \mu \mathrm{M})$ containing $\mathrm{MgCl} 2(25 \mu \mathrm{M})$, dNTPs $(10 \mu \mathrm{M})$ and Taq polymerase $(0.625 \mathrm{U} / 25 \mu \mathrm{l})$ (Thermo Fisher Scientific, Inc.). The PCR thermocycling (2720 Thermal Cycler; Applied Biosystems Life Technologies, Foster City, CA, USA) was performed with the following conditions: Initial denaturation for $95^{\circ} \mathrm{C}$ for $5 \mathrm{~min}$, followed by denaturation at $94^{\circ} \mathrm{C}$ for $30 \mathrm{~s}$, annealing (temperatures indicated in Table I) for $30 \mathrm{~s}$, and extension at $72^{\circ} \mathrm{C}$ for $30 \mathrm{~s}$ with the indicated number of cycles. This was followed by a final extension step at $72^{\circ} \mathrm{C}$ for $10 \mathrm{~min}$. Separation of the amplified PCR products was performed on a 2\% agarose gel (Merck Millipore, Karachi, Pakistan) with ethidium bromide (Sigma-Aldrich) for staining. The quantification of each PCR product band was determined using Image J 1.47 software (National Institutes of Health, Bethesda, MD, USA). Actin was used as a housekeeping gene to normalize the respective group of PCR products.
A Spatial reference memory

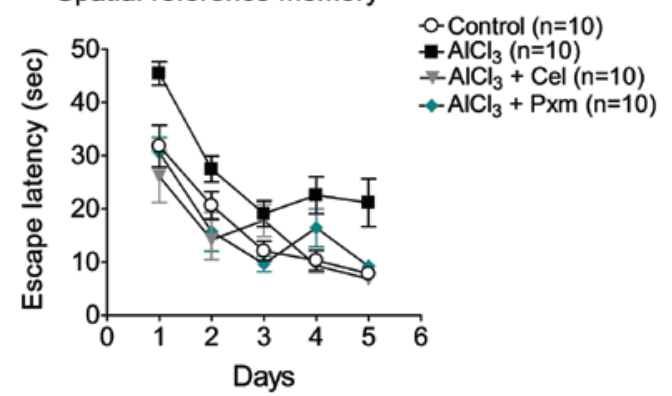

B

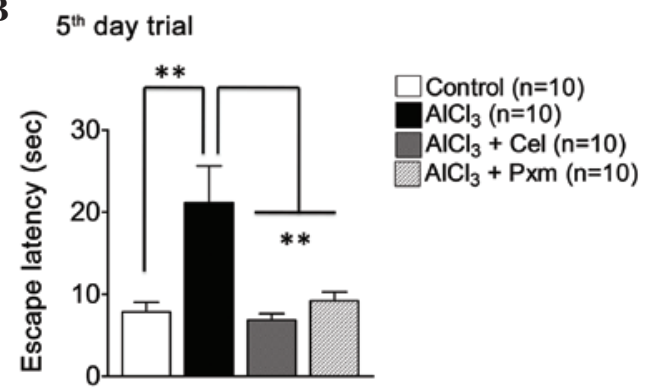

Figure 1. Morris water maze. (A) Comparison of learning and memory in the control, $\mathrm{AlCl}_{3}$-treated group and drug-treated groups. (B) 5th day trial, the average of the trial was plotted and the bar diagram shows the effect of the respective drugs on the escape latency. ${ }^{* *} \mathrm{P}<0.01$, compared with the $\mathrm{AlCl}_{3}$-treated group. Error bars represent the mean \pm standard error of the mean $(\mathrm{n}=10$; analysis of variance, followed by Bonferroni's comparison test). Cel, celecoxib; Pxm, piroxicam.

Assessment of ex-vivo antioxidant activity using a DPPH radical scavenging assay. The antioxidant activity in brain samples were evaluated using a DPPH (Sigma-Aldrich) radical scavenging assay, as described earlier (47) with certain modifications. The control, $\mathrm{AlCl}_{3}$-treated, celecoxib-treated and piroxicam-treated brain samples, with a $0.1 \mathrm{mg} / \mathrm{ml}$ protein concentration, were homogenized in $1 \mathrm{ml}$ methanol. Subsequently, $0.4 \mathrm{ml}$ of $0.1 \mathrm{mM}$ DPPH was added to the homogenized brain tissue samples which were designated as test samples. Pure DPPH solution was used as a control. The solutions were incubated at $37^{\circ} \mathrm{C}$ for $30 \mathrm{~min}$ and the absorbance was measured at $517 \mathrm{~nm}$ using an Optima SP300 spectrophotometer. The percentage DPPH inhibition was calculated by using the following formula, and was normalized to per/mg protein: DPHH inhibition $(\%)=$ (absorbance of control - absorbance of test sample / absorbance of control) x 100 . 
Statistical analysis. Data are expressed as the mean \pm standard error of the mean and the results were statistically analyzed using GraphPad Prism software. One way analysis of variance was used followed by Bonferroni's comparison test. $\mathrm{P}<0.05$ was considered to indicate a statistically significant difference.

\section{Results}

Effect of celecoxib and piroxicam on learning and memory. The control, $\mathrm{AlCl}_{3}$-treated, celecoxib and piroxicam treatment groups were investigated in a spatial reference memory task using a Morris water test (Fig. 1A). The result of the trial on the fifth day demonstrated a significant $(\mathrm{P}<0.01)$ improvement of memory in the celecoxib-treated mice $(6.84 \pm 0.76 \mathrm{sec})$ and piroxicam-treated mice $(9.20 \pm 1.08 \mathrm{sec})$, compared with the $\mathrm{AlCl}_{3}$-treated mice $(21.14 \pm 0.76 \mathrm{sec}$; Fig. 1B).

Effect of celecoxib and piroxicam on social behavior. Social affiliation and social novelty preference assessments were performed to examine the effect on sociability and preferences for social novelty. The comparison revealed that, in session I, the mice in the $\mathrm{AlCl}_{3}$-treated group spent less time $(28.8 \pm 8.97 \mathrm{sec})$ with the familiar mouse (mouse A), compared with the control group $(73.9 \pm 10.97 \mathrm{sec})$, however, the mice in the control group spent less time in the empty cage (Fig. 2A). During session I, the mice in the celecoxib and piroxicam treatment groups exhibited elevated social interaction, spending a longer duration with mouse A $(104.5 \pm 12.29 \mathrm{sec}$ and $70.90 \pm 12.84$ sec, respectively; Fig. 2A).

In session II, the time spent with the stranger mouse (mouse B), compared with mouse A was calculated. The control group spent significantly $(\mathrm{P}<0.001)$ more time $(57.5 \pm 6.18 \mathrm{sec})$ with mouse B, compared with mouse A, compared with the $\mathrm{AlCl}_{3}$-treated group $(23.2 \pm 3.31 \mathrm{sec})$, which demonstrated lack of social novelty preference (Fig. 2B). The celecoxib $(60.5 \pm 7.52 \mathrm{sec})$ and piroxicam treatment groups $(87.80 \pm 13.89 \mathrm{sec})$ exhibited a significant social novelty preference (Fig. 2B).

In determining the DI of the mice in session I, piroxicam $(0.7 \pm 0.02)$ exhibited significantly better effects than the celecoxib group $(0.75 \pm 0.03)$ when the two drug treatment groups were compared with the $\mathrm{AlCl}_{3}$-treated group $(0.50 \pm 0.5$; Fig. $2 \mathrm{C})$.

The DI calculated of the mice in session II indicated that the control group demonstrated better social novelty preference $(0.83 \pm 0.06)$, compared with the $\mathrm{AlCl}_{3}$-treated group $(0.64 \pm 0.01)$, which was noted to exhibit a deficit in social novelty preference (Fig. 2D). Treatment with celecoxib $(0.84 \pm 0.01)$ and piroxicam $(0.83 \pm 0.01)$ rescued social novelty in the diseased mice (Fig. 2D).

Effect of celecoxib and piroxicam on nesting behavior. Nesting behavior was assessed to determine the organizational and daily activities of living in mice. As shown in Fig. 3, the nest score of the $\mathrm{AlCl}_{3}$-treated group $(2.9 \pm 0.23)$ declined, compared with the control group (4.6 \pm 0.22$)$. Piroxicam was effective and improved nesting score (4.2 \pm 0.2$)$, whereas celecoxib (3.10 \pm 0.43$)$ was not effective (Fig. 3).

Effect of celecoxib and piroxicam on gene expression. In the present study, RT-qPCR analysis was performed to examine
A

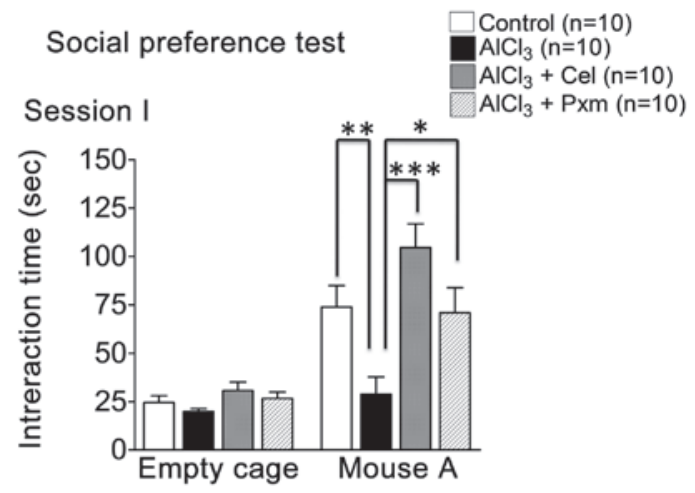

B

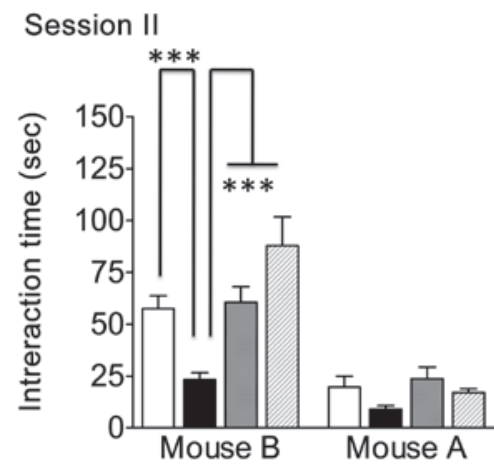

C

Discrimination index (session I)

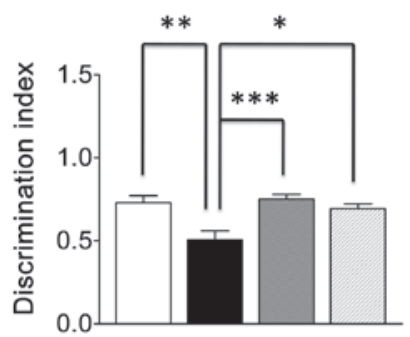

D

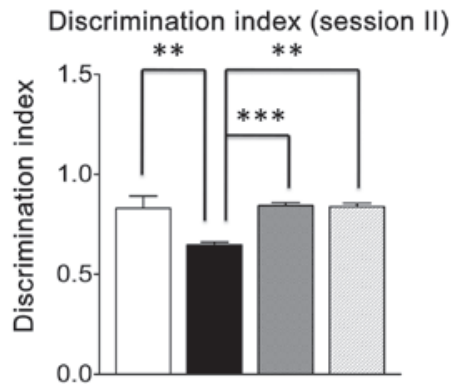

Figure 2. Sociability and social preference assessment in mice. (A) Session I graph showing the duration of interaction of different mice groups with the familiar mouse (mouse A) and an empty cage. (B) Session II graph showing the duration of interaction of mice with the stranger mouse (mouse B). (C) Discrimination index session I. (D) Discrimination index session II. ${ }^{*} \mathrm{P}<0.05,{ }^{* *} \mathrm{P}<0.01$ and ${ }^{* * *} \mathrm{P}<0.001$, compared with the $\mathrm{AlCl}_{3}$-treated group. Error bars represent the mean \pm standard error of the mean $(n=10$; analysis of variance followed by Bonferroni's comparison test). Cel, celecoxib; Pxm, piroxicam.

the effect of drug treatment on gene expression. In the hippocampus, there was an increase in the levels of COX-I (2.8 \pm 0.34$)$ in the $\mathrm{AlCl}_{3}$-treated group, compared with the control group $(0.74 \pm 0.15)$, however, only piroxicam treatment decreased the expression of COX-I significantly $(0.9 \pm 0.32)$, whereas, celecoxib was not effective (Fig. 4A). 
Nesting behavior

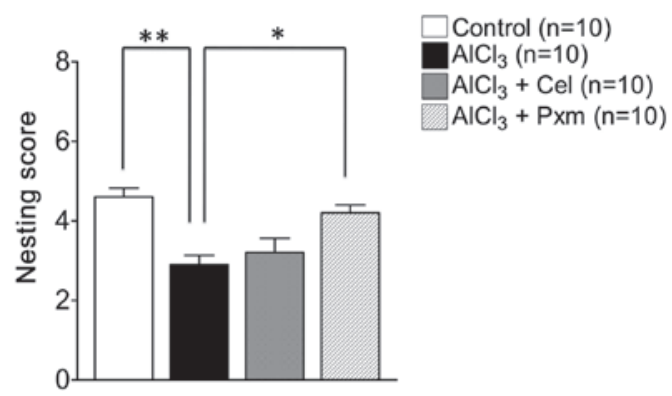

Figure 3. Nesting behavior. Comparison between the control, $\mathrm{AlCl}_{3}$, $\mathrm{AlCl}_{3}+\mathrm{Cel}$ and $\mathrm{AlCl}_{3}+\mathrm{Pxm}$ treatment groups. ${ }^{*} \mathrm{P}<0.05$ and ${ }^{* *} \mathrm{P}<0.01$, compared with the $\mathrm{AlCl}_{3}$-treated group. Error bars represent the mean \pm standard error of the mean $(n=10$; analysis of variance followed by Bonferroni's comparison test). Cel, celecoxib; Pxm, piroxicam.

In the cortex, a significant $(\mathrm{P}<0.01)$ increase in the level of COX-I $(1.57 \pm 0.16)$ was observed in the $\mathrm{AlCl}_{3}$-treated group, compared with the control group $(0.8 \pm 0.03)$. Piroxicam treatment resulted in significant $(\mathrm{P}<0.05)$ downregulation in the expression of COX-I $(0.9 \pm 0.06)$, compared with the $\mathrm{AlCl}_{3}$-treated group. Celecoxib treatment $(1.24 \pm 0.2)$ was not found to be effective (Fig. 4B).

In the hippocampus, upregulation in the levels of COX-II $(2.65 \pm 0.43)$ were observed in the $\mathrm{AlCl}_{3}$-treated group, compared with the control group $(0.7 \pm 0.09$; Fig. 4 C), exhibiting inflammatory stress. Celecoxib treatment resulted in significant $(\mathrm{P}<0.01)$ downregulation in the levels of COX-II $(1 \pm 0.24)$, indicating its selective effect on the gene expression of COX-II, whereas piroxicam treatment was not effective (1.60 \pm 0.23 ; Fig. 4C).

In the cortex, the levels of COX-II were elevated in the $\mathrm{AlCl}_{3}$-treated group $(2.4 \pm 0.30)$, compared with the control group $(0.90 \pm 0.20)$. The celecoxib and piroxicam treatment groups exhibited downregulated levels of COX-II $(0.90 \pm 0.13$ and $1.46 \pm 0.06$, respectively), compared with the $\mathrm{AlCl}_{3}$-treated group (Fig. 4D).

Ex-vivo DPPH assay. To investigate the effect of celecoxib and Piroxicam on oxidative stress, a DPPH assay was performed in the hippocampus and cortex of the brain tissues of the mice in the treatment groups. The results demonstrated that the $\mathrm{AlCl}_{3}$-treated group exhibited a substantial load of free radicals and a decreased percentage of DPPH inhibition (14 $\pm 2.7 \%)$ in the hippocampus, also indicative of decreased endogenous anti-oxidants, compared with the control (44.6 $\pm 1.07 \%$; Fig. 5A). The celecoxib-treated group (28.2 $\pm 1.8 \%)$ exhibited a significant $(\mathrm{P}<0.001)$ increase in the percentage inhibition of free radicals in the hippocampus, whereas the piroxicam-treated group was less effective $(24 \pm 1.51 \%$; $\mathrm{P}<0.01 ;$ Fig. $5 \mathrm{~A})$.

In the cortex, the $\mathrm{AlCl}_{3}$-treated group $(27.51 \pm 14.87 \%)$ exhibited increased oxidative stress resulting in free radical production, compared with the control group $(71.54 \pm 4.85 \%$; Fig. 5B). Celecoxib treatment led to the effective inhibition of the free radicals $(72.4 \pm 5.4)$ induced by $\mathrm{AlCl}_{3}$. Similarly, piroxicam treatment led to increased free radical scavenging activity $(65.2 \pm 6.02 \%)$, compared with the $\mathrm{AlCl}_{3}$-treated group (Fig. 5B).
A
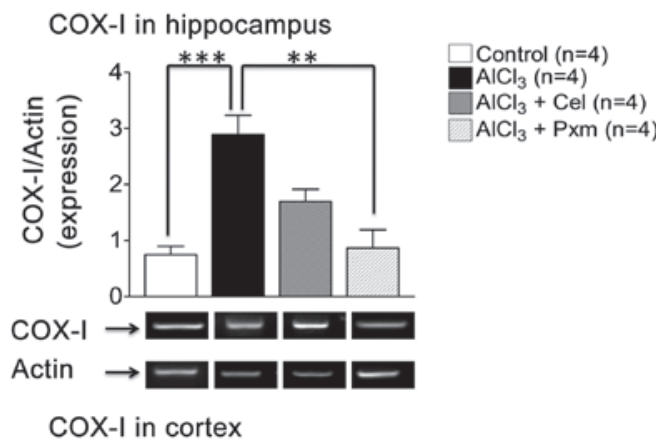

B

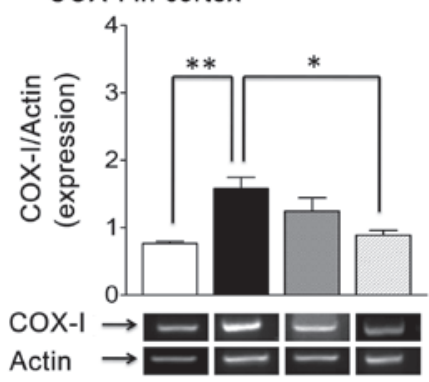

C

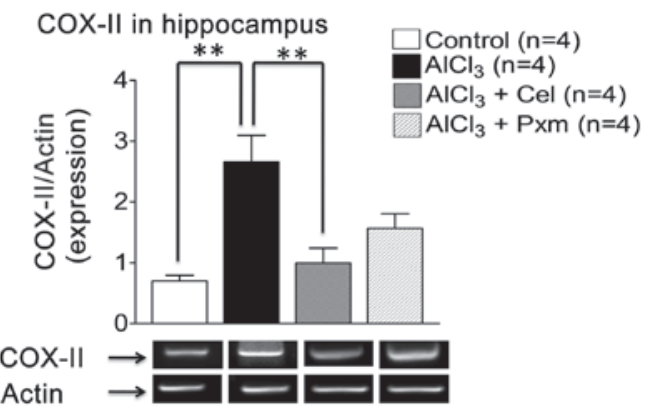

D

COX-II in cortex

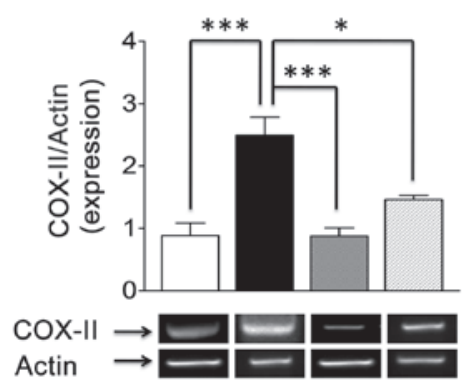

Figure 4. Expression levels of COX-I in the (A) hippocampus and (B) cortex Comparison of the control, $\mathrm{AlCl}_{3}, \mathrm{AlCl}_{3}+\mathrm{Cel}$ and $\mathrm{AlCl}_{3}+\mathrm{Pxm}$ treatment groups are shown. Data represents the mean \pm standard error of the mean. Expression levels of COX-II in the (C) hippocampus and (D) cortex. Comparison between the control, $\mathrm{AlCl}_{3}, \mathrm{AlCl}_{3}+\mathrm{Cel}$ and $\mathrm{AlCl}_{3}+\mathrm{Pxm}$-treated groups are shown. Data represent the mean \pm standard error of the mean. ${ }^{*} \mathrm{P}<0.05,{ }^{* *} \mathrm{P}<0.01$ and ${ }^{* * *} \mathrm{P}<0.001$, compared with the $\mathrm{AlCl}_{3}$-treated group (analysis of variance followed by Bonferroni's comparison test). COX, cyclooxygenase; Cel, celecoxib; Pxm, piroxicam.

\section{Discussion}

The present study attempted to identify which COX enzyme inhibition is predominantly responsible for the improvement in hippocampal- and cortex-dependent cognitive function in the $\mathrm{AlCl}_{3}$-treated mice model to determine the role of NSAIDs in neurodegenerative disorders. The present study demonstrated the significant effect of celecoxib and piroxicam on learning and memory, determined using the Morris water maze test. The 
A

DPPH scavenging activity (hippocampus)

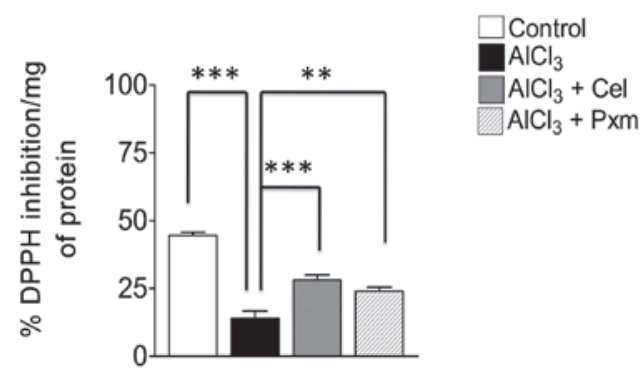

B

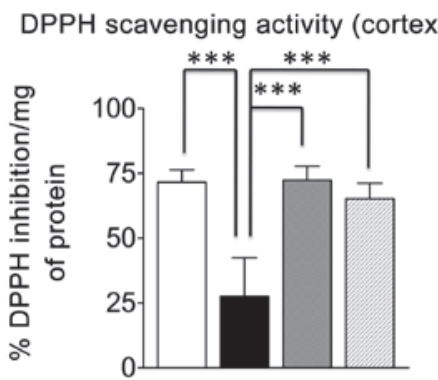

Figure 5. Percentage DPPH inhibition/mg of protein in the (A) hippocampus and (B) cortex. Comparison between the control, $\mathrm{AlCl}_{3}$ group, $\mathrm{AlCl}_{3}+\mathrm{Cel}$ and $\mathrm{AlCl}_{3}+\mathrm{Pxm}$ treatment groups are shown in $100 \mu \mathrm{g} / \mathrm{ml}$ brain tissue samples. Error bars represent the mean \pm standard error of the mean. ${ }^{* * *} \mathrm{P}<0.01$ and ${ }^{* * * *} \mathrm{P}<0.001$, compared with the $\mathrm{AlCl}_{3}$-treated group (analysis of variance followed by Bonferroni's comparison test). DPPH, 2,2-Diphenyl-1-picrylhydrazyl; Cel, celecoxib; Pxm, piroxicam.

two drugs exhibited similar efficacy in the Morris water maze, which is a hippocampus-dependent memory task. These results are concordance with those of earlier studies, which reported that selective COX-II inhibition restores memory function in APP-overexpressing transgenic mice (48) and selective COX-I inhibition promotes learning (11). Treatment with celecoxib and piroxicam demonstrated memory enhancing effects by decreasing the expression levels of the COX-I and II isoforms in mice, suggesting that decreased expression levels may have decreased inflammation and increased memory. Another possible reason for the enhanced memory in the COX-II inhibitor-treated group is the inhibition of overexpressed COX-II in the hippocampal neurons, resulting in improved memory. COX-1 inhibition may improve memory through decreasing inflammation, however, the exact mechanism remains to be elucidated.

Social affiliation and social novelty preference are amygdala- and cortex-dependent behaviors (49). The present study suggested that celecoxib exhibited improved effects on social affiliation (session I), whereas piroxicam exhibited a more marked effect on social novel preference. It has been revealed that COX-II inhibition is beneficial in suppressing the stress induced by elevated COX-II enzyme in rat brain (50). Similarly, the role of piroxicam in novel social preference is a novel finding. The present study investigated, for the first time, the effect of the two $\mathrm{COX}$ inhibitors in an $\mathrm{AlCl}_{3}$-induced neurotoxicity mouse model, and demonstrated that COX inhibitors assist in improving social recognition memory, suggesting their potential role in neurodegenerative conditions accompanied with social memory problems. Further investigations are required to determine the importance of the effect, and to investigate the mechanism through which they act to improve these symptoms in neurodegeneration.

Nest building is a common behavior in mice and is associated with the maintenance of body temperature (51). It is a prefrontal cortex- and hippocampus-based behavior (52), and it has been reported that damage in the medial prefrontal cortex and hippocampus leads to the reduction in nesting material consumption and disturbs the quality of the nest $(52,53)$. The present study revealed that piroxicam improved the quality of the nest and reversed Al-induced impairment, whereas, celecoxib failed to produce a significant effect. These are novel findings and suggest an additional pharmacological role of piroxicam, however, the exact underlying mechanism remains to be elucidated.

In the present study, the levels of COX-I and COX-II were elevated in the hippocampus and cortex in the $\mathrm{AlCl}_{3}$-treated group, and piroxicam reduced the expression levels of COX-I in hippocampus and cortex, which may be its underlying mechanism in improving cognitive functions. This drug has not been investigated previously for its effect on gene expression in the $\mathrm{AlCl}_{3}$-treated mouse model. Other COX-I inhibitors have been investigated and have offered protection against mild to moderate cognitive impairment in patients with neurodegenerative disease (54). Celecoxib treatment also led to reduced expression levels of COX-II in the hippocampus and cortex, suggesting its beneficial role in reducing neuroinflammation, which differs to earlier reports that selective COX-II inhibitors fail to demonstrate beneficial effects in patients with neurodegenerative disease $(7,55)$. Therefore, these findings suggested that depressive symptoms of disease may be treated using celecoxib.

It has already been accepted and established that oxidative stress is one of the hallmarks of several neurological disorders, particularly $\mathrm{AD}$ (56). In the present study the $\mathrm{AlCl}_{3}$-treated model exhibited increased oxidative stress in the brain tissue, compared with the control, which was concordant with an earlier study, confirming the role of $\mathrm{Al}$ in producing oxidative damage in brain tissues (57). The ex-vivo anti-oxidant activity of piroxicam and celecoxib exhibited increased free radical inhibition in the hippocampus, compared with the $\mathrm{AlCl}_{3}$-treated group. In the cortex, the two drugs equally decreased oxidative stress, indicating their therapeutic potential in neurodegenerative disorders.

In the present study, comparison of piroxicam and celecoxib in reference to Al-induced neurodegeneration was performed for the first time. The ability of piroxicam to improve organizational behavior and sociability are significant findings, suggesting the role of piroxicam in various neurodegenerative disorders. Celecoxib treatment markedly improved cognitive functions, including learning, memory and anxious behavior. Its effect on social activity was also examined, which exhibited positive effects as a novel finding. The two drugs also improved $\mathrm{AlCl}_{3}$-induced neuroinflammation and decreased oxidative stress, which demonstrates their potential for use in neurodegenerative diseases. These results suggested that COX enzymes are important in neuropathology and have potential as drug targets in neurodegeneration. This investigation can be broadened to further investigate the possible molecular mechanisms of these drugs in other neurodegenerative conditions. 


\section{Acknowledgements}

This study was supported by the Atta-ur-Rahman School of Applied Biosciences, National University of Sciences and Technology and the SmallResearchProject Grants 2012,College of Medicine, Alfaisal University (grant. no. 313090202133).

\section{References}

1. Choi SH, Aid S, Choi U and Bosetti F: Cyclooxygenases-1 and -2 differentially modulate leukocyte recruitment into the inflamed brain. Pharmacogenomics J 10: 448-457, 2010.

2. McGeer PL, Itagaki S, Tago $\mathrm{H}$ and McGeer EG: Reactive microglia in patients with senile dementia of the Alzheimer type are positive for the histocompatibility glycoprotein HLA-DR Neurosci Lett 79: 195-200, 1987.

3. Haga S, Akai K and Ishii T: Demonstration of microglial cells in and around senile (neuritic) plaques in the Alzheimer brain. An immunohistochemical study using a novel monoclonal antibody. Acta Neuropathol 77: 569-575, 1989

4. Wisniewski HM, Wegiel J, Wang KC and Lach B: Ultrastructural studies of the cells forming amyloid in the cortical vessel wall in Alzheimer's disease. Acta Neuropathol 84: 117-127, 1992.

5. McGeer PL, Schulzer $M$ and McGeer EG: Arthritis and anti-inflammatory agents as possible protective factors for Alzheimer's disease: A review of 17 epidemiologic studies. Neurology 47: 425-432, 1996.

6. in t'Veld BA, Ruitenberg A, Hofman A, Launer LJ, van Duijn CM, Stijnen T, Breteler MM and Stricker BH: Nonsteroidal antiinflammatory drugs and the risk of Alzheimer's disease. N Engl J Med 345: 1515-1521, 2001.

7. McGeer PL and McGeer EG: NSAIDs and Alzheimer disease: Epidemiological, animal model and clinical studies. Neurobiol Aging 28: 639-647, 2007.

8. Lim GP, Yang F, Chu T, Chen P, Beech W, Teter B, Tran T, Ubeda O, Ashe KH, Frautschy SA and Cole GM: Ibuprofen suppresses plaque pathology and inflammation in a mouse model for Alzheimer's disease. J Neurosci 20: 5709-5714, 2000.

9. Lim GP, Yang F, Chu T, Gahtan E, Ubeda O, Beech W, Overmier JB, Hsiao-Ashec K, Frautschy SA and Cole GM: Ibuprofen effects on Alzheimer pathology and open field activity in APPsw transgenic mice. Neurobiol Aging 22: 983-991, 2001.

10. McKee AC, Carreras I, Hossain L, Ryu H, Klein WL, Oddo S, LaFerla FM, Jenkins BG, Kowall NW and Dedeoglu A: Ibuprofen reduces Abeta, hyperphosphorylated tau and memory deficits in Alzheimer mice. Brain Res 1207: 225-236, 2008.

11. Choi SH, Aid S, Caracciolo L, Minami SS, Niikura T, Matsuoka Y, Turner RS, Mattson MP and Bosetti F: Cyclooxygenase-1 inhibition reduces amyloid pathology and improves memory deficits in a mouse model of Alzheimer's disease. J Neurochem 124: 59-68, 2013.

12. Williams CS and DuBois RN: Prostaglandin endoperoxide synthase: Why two isoforms? Am J Physiol 270: G393-G400, 1996.

13. Candelario-Jalil E: A role for cyclooxygenase-1 in beta-amyloid-induced neuroinflammation. Aging (Albany NY) 1: 350-353, 2009.

14. Kelley KA, Ho L, Winger D, Freire-Moar J, Borelli CB, Aisen PS and Pasinetti GM: Potentiation of excitotoxicity in transgenic mice overexpressing neuronal cyclooxygenase-2. Am J Pathol 155: 995-1004, 1999.

15. Hoozemans JJ, Rozemuller AJ, Janssen I, De Groot CJ, Veerhuis R and Eikelenboom P: Cyclooxygenase expression in microglia and neurons in Alzheimer's disease and control brain. Acta Neuropathol 101: 2-8, 2001.

16. Li XB, Zheng H, Zhang ZR, Li M, Huang ZY, Schluesener HJ, Li YY and Xu SQ: Glia activation induced by peripheral administration of aluminum oxide nanoparticles in rat brains. Nanomedicine 5: 473-479, 2009.

17. Garcia-Bueno B, Serrats J and Sawchenko PE: Cerebrovascular cyclooxygenase-1 expression, regulation and role in hypothalamic-pituitary-adrenal axis activation by inflammatory stimuli. J Neurosci 29: 12970-12981, 2009.

18. Matousek SB, Hein AM, Shaftel SS, Olschowka JA, Kyrkanides S and O'Banion MK: Cyclooxygenase-1 mediates prostaglandin $\mathrm{E}(2)$ elevation and contextual memory impairment in a model of sustained hippocampal interleukin-1beta expression. J Neurochem 114: 247-258, 2010.
19. Choi SH and Bosetti F: Cyclooxygenase-1 null mice show reduced neuroinflammation in response to beta-amyloid. Aging (Albany NY) 1: 234-244, 2009.

20. Choi SH, Langenbach R and Bosetti F: Genetic deletion or pharmacological inhibition of cyclooxygenase-1 attenuate lipopolysaccharide-induced inflammatory response and brain injury. FASEB J 22: 1491-1501, 2008.

21. Candelario-Jalil E, de Oliveira AC, Gräf S, Bhatia HS, Hüll M, Muñoz E and Fiebich BL: Resveratrol potently reduces prostaglandin E2 production and free radical formation in lipopolysaccharide-activated primary rat microglia. J Neuroinflammation 4: 25, 2007.

22. Candelario-Jalil E, Taheri S, Yang Y, Sood R, Grossetete M, Estrada EY, Fiebich BL and Rosenberg GA: Cyclooxygenase inhibition limits blood-brain barrier disruption following intracerebral injection of tumor necrosis factor-alpha in the rat. J Pharmacol Exp Ther 323: 488-498, 2007.

23. Ahmed T and Gilani AH: A comparative study of curcuminoids to measure their effect on inflammatory and apoptotic gene expression in an $A \beta$ plus ibotenic acid-infused rat model of Alzheimer's disease. Brain Res 1400: 1-18, 2011.

24. Masferrer JL, Zweifel BS, Seibert K and Needleman P: Selective regulation of cellular cyclooxygenase by dexamethasone and endotoxin in mice. J Clin Invest 86: 1375-1379, 1990.

25. Choi SH, Aid S and Bosetti F: The distinct roles of cyclooxygenase-1 and -2 in neuroinflammation: Implications for translational research. Trends Pharmacol Sci 30: 174-181, 2009.

26. Hoozemans JJ, Rozemuller JM, van Haastert ES, Veerhuis R and Eikelenboom P: Cyclooxygenase-1 and -2 in the different stages of Alzheimer's disease pathology. Curr Pharm Des 14: 1419-1427, 2008.

27. Niwa K, Araki E, Morham SG, Ross ME and Iadecola C: Cyclooxygenase-2 contributes to functional hyperemia in whisker-barrel cortex. J Neurosci 20: 763-770, 2000.

28. Yang $\mathrm{H}$ and Chen $\mathrm{C}$ : Cyclooxygenase-2 in synaptic signaling. Curr Pharm Des 14: 1443-1451, 2008.

29. Pasinetti GM and Aisen PS: Cyclooxygenase-2 expression is increased in frontal cortex of Alzheimer's disease brain. Neuroscience 87: 319-324, 1998.

30. Fujimi K, Noda K, Sasaki K, Wakisaka Y, Tanizaki Y, Iida M, Kiyohara Y, Kanba S and Iwaki T: Altered expression of COX-2 in subdivisions of the hippocampus during aging and in Alzheimer's disease: The Hisayama study. Dement Geriatr Cogn Disord 23: 423-431, 2007.

31. Yermakova AV and O'Banion MK: Downregulation of neuronal cyclooxygenase-2 expression in end stage Alzheimer's disease. Neurobiol Aging 22: 823-836, 2001.

32. Tocco G, Freire-Moar J, Schreiber SS, Sakhi SH, Aisen PS and Pasinetti GM: Maturational regulation and regional induction of cyclooxygenase-2 in rat brain: Implications for Alzheimer's disease. Exp Neurol 144: 339-349, 1997.

33. Miettinen S, Fusco FR, Yrjünheikki J, Keinänen R, Hirvonen T, Roivainen R, Närhi M, Hökfelt T and Koistinaho J: Spreading depression and focal brain ischemia induce cyclooxygenase-2 in cortical neurons through N-methyl-D-aspartic acid-receptors and phospholipase A2. Proc Natl Acad Sci USA 94: 6500-6505, 1997.

34. Greenberg ER and Baron JA: Aspirin and other nonsteroid anti-inflammatory drugs as cancer-preventive agents. IARC Sci Publ 91-98, 1996.

35. Abd-Elhady RM, Elsheikh AM and Khalifa AE: Anti-amnestic properties of Ginkgo biloba extract on impaired memory function induced by aluminum in rats. Int J Dev Neurosci 31: 598-607, 2013.

36. Belaid-Nouira Y, Bakhta H, Bouaziz M, Flehi-Slim I, Haouas Z and Ben Cheikh H: Study of lipid profile and parieto-temporal lipid peroxidation in $\mathrm{AlCl}_{3}$ mediated neurotoxicity. Modulatory effect of fenugreek seeds. Lipids Health Dis 11: 16, 2012.

37. Meyer-Baron M, Schäper M, Knapp G and van Thriel C: Occupational aluminum exposure: Evidence in support of its neurobehavioral impact. Neurotoxicology 28: 1068-1078, 2007.

38. Hashmi AN, Yaqinuddin A and Ahmed T: Pharmacological effects of Ibuprofen on learning and memory, muscarinic receptors genes expression and APP isoforms levels in Pre-frontal cortex of AlCl3-induced toxicity mouse model. Int J Neurosci 125: 277-287, 2015.

39. Bondy SC: The neurotoxicity of environmental aluminum is still an issue. Neurotoxicology 31: 575-581, 2010. 
40. Andrasi E, Páli N, Molnár Z and Kösel S: Brain aluminum, magnesium and phosphorus contents of control and Alzheimer-diseased patients. J Alzheimers Dis 7: 273-284, 2005.

41. National Research Council. Guide for the care and use of laboratory animals. Washington, D.C. National Academy Press, 1996

42. Thirunavukkarasu SV, Venkataraman S, Raja S and Upadhyay L: Neuroprotective effect of Manasamitra vatakam against aluminium induced cognitive impairment and oxidative damage in the cortex and hippocampus of rat brain. Drug Chem Toxicol 35: 104-115, 2012.

43. Ahmed T and Gilani AH: Inhibitory effect of curcuminoids on acetylcholinesterase activity and attenuation of scopolamine-induced amnesia may explain medicinal use of turmeric in Alzheimer's disease. Pharmacol Biochem Behav 91: 554-559, 2009.

44. Meeker HC, Chadman KK, Heaney AT and Carp RI: Assessment of social interaction and anxiety-like behavior in senescence-accelerated-prone and -resistant mice. Physiol Behav 118: 97-102, 2013

45. Deacon R: Assessing burrowing, nest construction and hoarding in mice. J Vis Exp e2607, 2012.

46. Ahmed T, Enam SA and Gilani AH: Curcuminoids enhance memory in an amyloid-infused rat model of Alzheimer's disease. Neuroscience 169: 1296-1306, 2010.

47. Habila N, Agbaji AS, Ladan Z, Bello IA, Haruna E, Dakare MA and Atolagbe TO: Evaluation of in vitro activity of essential oils against trypanosoma brucei brucei and trypanosoma evansi. J Parasitol Res 2010, 2010.

48. Kotilinek LA, Westerman MA, Wang Q, Panizzon K, Lim GP Simonyi A, Lesne S, Falinska A, Younkin LH, Younkin SG, et al Cyclooxygenase-2 inhibition improves amyloid-beta-mediated suppression of memory and synaptic plasticity. Brain 131: 651-664, 2008.
49. Bickart KC, Hollenbeck MC, Barrett LF and Dickerson BC: Intrinsic amygdala-cortical functional connectivity predicts social network size in humans. J Neurosci 32: 14729-14741, 2012.

50. Guo JY, Li CY, Ruan YP, Sun M, Qi XL, Zhao BS and Luo F: Chronic treatment with celecoxib reverses chronic unpredictable stress-induced depressive-like behavior via reducing cyclooxygenase-2 expression in rat brain. Eur J Pharmacol 612: 54-60, 2009.

51. Min Z, Wang S, Wu J and Zhang S: Impairment of nesting behavior in APPswe/PS1dE9 mice. Life Sci J 10: 1942-1945, 2013.

52. Deacon RM, Croucher A and Rawlins JN: Hippocampal cytotoxic lesion effects on species-typical behaviours in mice. Behav Brain Res 132: 203-213, 2002.

53. Holson RR and Walker C: Mesial prefrontal cortical lesions and timidity in rats. II. Reactivity to novel stimuli. Physiol Behav 37: 231-238, 1986.

54. Rogers J, Kirby LC, Hempelman SR, Berry DL, McGeer PL, Kaszniak AW, Zalinski J, Cofield M, Mansukhani L and Willson P: Clinical trial of indomethacin in Alzheimer's disease. Neurology 43: 1609-1611, 1993.

55. Reines SA, Block GA, Morris JC, Liu G, Nessly ML, Lines CR, Norman BA and Baranak CC; Rofecoxib Protocol 091 Study Group: Rofecoxib: No effect on Alzheimer's disease in a 1-year, randomized, blinded, controlled study. Neurology 62: 66-71, 2004.

56. Smith MA, Rottkamp CA, Nunomura A, Raina AK and Perry G: Oxidative stress in Alzheimer's disease. Biochim Biophys Acta 1502: 139-144, 2000.

57. Chazot $\mathrm{G}$ and Broussolle E: Alterations in trace elements during brain aging and in Alzheimer's dementia. Prog Clin Biol Res 380: 269-281, 1993. 